\title{
Stage IVB Lung Cancer AJCC v8
}

National Cancer Institute

\section{Source}

National Cancer Institute. Stage IVB Lung Cancer AJCC v8. NCI Thesaurus. Code C136484.

Stage IVB includes: Any T, Any N, M1c. M1c: T umor with multiple extrathoracic metastases in a single organ or in multiple organs. (AJCC 8th ed.) 